www.jmscr.igmpublication.org

Index Copernicus Value: 79.54

ISSN (e)-2347-176x ISSN (p) 2455-0450

crossrefDOI: https://dx.doi.org/10.18535/jmscr/v7i2.157

\title{
Predictors of Acute Urinary Retention in Benign Prostatic Hyperplasia - A Comparative Study in Patients with Acute Urinary Retention and Without Retention
}

\author{
Velmurugan $P^{1}$, Bhaskara Prakash $A R^{2}$, Sriram $K^{3}$, Venkat Ramanan $S^{4}$, Natarajan $K^{5}$ \\ ${ }_{1,2,3,4,5}$ Sri Ramachandra Institute of Higher Education and Research, Porur, Chennai, India \\ *Corresponding Author \\ Bhaskara Prakash AR \\ Sri Ramachandra Institute of Higher Education and Research, Porur, Chennai, India \\ Email:velumsdoc@rediffmail.com
}

\begin{abstract}
Aim of the Study: To accurately determine factors that predict acute urinary retention in patients with benign prostatic hyperplasia $(B P H)$ by comparing patients presenting with acute urinary retention (AUR) to patients without urinary retention.

Study Design: Prospective observational analytical study.

Materials and Methods: All men presenting with lower urinary tract symptoms (LUTS), with and without urinary retention, clinically and radiologically diagnosed to have BPH were compared. 63 patients were enrolled in the study. Among them, 32 patients presented with AUR and 31 patients presented with LUTS only. International prostate symptom scoring (IPSS) grading, digital rectal examination (DRE) and abdominal ultrasonogram (USG) were used to assess symptoms, clinical prostate enlargement and prostate size respectively.
\end{abstract}

Parameters Compared: Age , comorbid illnesses, previous history of urinary retention, presence of urinary tract infection, IPSS symptom severity and grading, prostate size grading as per digital rectal examination, size of prostate and intravesical protrusion of prostate (IPP) grading as per ultrasound study, thickness of bladder wall(BWT)by ultrasound, and serum prostatic specific antigen (PSA) level.

Statistical Analysis: Statistical package for social sciences, version 12.0.2 (SPSS, Inc. Chicago, USA) was used for statistical analysis. The mean, standard deviation, minimal, maximal values were calculated and the baseline parameters values in both groups were analyzed using student unpaired $t$ test. All discrete variables were analyzed by Chi Square test. All data were analyzed using SPSS computer program and $p$ $<0.05$ was considered statically significant.

Conclusion: Symptom severity, previous AUR episodes, high serum PSA levels, increased size of prostate , increased bladder wall thickness, increased intravesical prostatic projection length are accurate predictors of acute urinary retention in patients with benign prostatic hyperplasia. Those patients who are at risk can be offered earlier treatment options, could be either medical or surgical intervention to prevent AUR.

Keywords: Acute urinary retention, benign prostatic hyperplasia, prostate specific antigen, intravesical protrusion prostate, digital rectal examination. 


\section{Introduction}

In men older than 50 years, benign prostatic hyperplasia is a common disease. The incidence of $\mathrm{BPH}$ in this age group is about $19-30 \%{ }^{1}$. Benign prostatic hyperplasia is a progressive disease. Acute Urinary Retention (AUR) is one of the long-term outcomes of benign prostatic hyperplasia. ${ }^{2}$

The risk of acute urinary retention is higher in a patient with $\mathrm{BPH}$ when compared to the general population. The estimated incidence rate is 5-25 per 1000 person-years. $^{3}$ It is approximately $0.5 \%-2.5 \%$ per year ${ }^{4}$. Risk is cumulative which increases with an increase in age.

AUR is characterized by the inability to void, increasing pain, and need for catheterization. The treatment part of AUR is painful and timeconsuming with follow-up visits and an attempt of trial voiding. If trial voiding fails, the patient may require surgery.

AUR may be classified as that related to $\mathrm{BPH}$ or not related to BPH. It can be either spontaneous or precipitated. One of the prophylactic measures attempted to prevent AUR in men with moderate to severe LUTS and large sized prostate, is the use of 5 alpha reductase inhibitors. Alpha blockers have also been used in symptomatic BPH patients to prevent AUR and can aid in voiding following catheter removal. However conclusive evidence to prove reduction of risk of AUR with the use of finasteride and $\alpha$-blockers is still lacking.

Our study was an attempt to determine the factors that can predict which patients can go in for urinary retention by comparing patients who had AUR with patients presented only with LUTS without urinary retention. Those patients who are at increased risk can be offered earlier treatment options, either medical management ( $\alpha$ blockers or $5 \alpha$ reductase inhibitors) or surgery (transurethral resection of prostate- TURP) aiming in the primary prevention of AUR.

\section{Aim of the study}

To accurately determine factors that predict acute urinary retention in patients with benign prostatic hyperplasia by comparing patients presenting with acute urinary retention to patients without urinary retention.

\section{Materials and methods \\ Group1:}

Patients $(n=32)$ presenting with urinary retention.

\section{Group2:}

Patients $(n=31)$ with LUTS without urinary retention.

The diagnosis of BPH in all patients was confirmed clinically and radiologically. All patients age, comorbid illnesses, previous history of AUR were recorded.

\section{Assessment of symptoms}

Symptoms were assessed with IPSS grading system, mild: 0 - 7; moderate: 8 -19; severe: $20-35$.

The patients with AUR were asked to record their symptoms for one month before urinary retention.

Assessment of prostate size by DRE: (Tab 1$)^{5}$

On DRE, apart from grading of enlargement, consistency, symmetry of the prostate gland, presence or obliteration of median furrow and lateral sulci were assessed. The presence of nodules was also recorded.

Tab 1 Digital rectal examination grading

\begin{tabular}{|l|l|}
\hline Size & Digital rectal examination (DRE) grading \\
\hline Normal & Encroaches 0 to $1 \mathrm{~cm}$ rectal lumen \\
\hline I & Encroaches 1 to $2 \mathrm{~cm}$ \\
\hline II & Encroaches 2 to $3 \mathrm{~cm}$ \\
\hline III & Encroaches 3 to $4 \mathrm{~cm}$ \\
\hline IV & Encroaches $>4 \mathrm{~cm}$ \\
\hline
\end{tabular}

USG study was done transabdominally to estimate prostate size, bladder wall thickness (BWT) and intravesical protrusion of prostate (IPP) ${ }^{5}$. Prostate size was calculated using prostate ellipsoid formula$\pi / 6 \times$ anteroposterior $(\mathrm{AP}) \times$ transverse $(\mathrm{T}) \times$ sagittal (S) diameter. Depending upon the size of enlarged prostate, ultrasound grading (tab 2) can be as follows

Tab 2 - Usg - size grading

\begin{tabular}{|l|c|}
\hline NORMAL & $<20 \mathrm{gms}$ \\
\hline I & $20-40 \mathrm{gms}$ \\
\hline II & $40-60 \mathrm{gms}$ \\
\hline III & $60-90 \mathrm{gms}$ \\
\hline IV & $>90 \mathrm{gms}$ \\
\hline
\end{tabular}


Bladder wall thickness was measured by USG, keeping the probe suprapubically from the anterior wall of the bladder in a partially filled bladder with $150 \mathrm{ml}$. The degree of intravesical protrusion of prostate (IPP) can be graded by measuring from the tip of the protruding prostate perpendicularly to the circumference of the bladder at the base of the prostate gland.

Depending upon the length of intravesical protrusion of grading (tab 3$)^{5}$ are as follows

Tab 3 Grading of intravesical protrusion of prostate

\begin{tabular}{|l|c|}
\hline Grades & Length of protrusion \\
\hline Grade 1 & $<5 \mathrm{~mm}$ \\
\hline Grade 2 & $5-10 \mathrm{~mm}$ \\
\hline Grade 3 & $>10 \mathrm{~mm}$ \\
\hline
\end{tabular}

Routine haemogram and blood biochemistry were performed. Urine analysis / urine culture and sensitivity was done by collecting mid-stream samples in group 2 and samples were collected directly from urethral catheter in group1 patients.

Serum PSA assessed with immunoradiometric assay. Samples were taken in OP clinic or in the patients ward before insertion of the catheter. If patient presents to our clinic with inserted catheter, latest PSA done at outpatient clinic were used for comparison. In suspicion of Carcinoma prostate trans rectal biopsy were performed. Patient with biopsy proved Carcinoma prostate, were excluded from the study.

In our study among the 63 patients, 2 patients in group 1 (one having treatment with antidepressants, one with neurogenic bladder dysfunction) and one in group 2 (who had biopsy confirmed carcinoma prostate) were excluded.

The mean, standard deviation, minimal, maximal values were calculated and the baseline parameters values in both groups were analyzed using student unpaired t test. All discrete variables were analyzed by Chi Square test. All data were analyzed using SPSS computer program and $\mathrm{p}<0.05$ was considered statically significant. Statiscal package for social sciences, version 12.0.2 (SPSS, Inc., Chicago, USA) was used for statistical analysis.

\section{Observation and Results}

The following parameters were compared between group 1 and group 2. (Tab 4)

\section{Age:}

Age distribution: Most of the patients in both groups belong to $51-60$ years age group. [Group1 $(\mathrm{n}=12)$, Group2 $(\mathrm{n}=13)]$.

Age group: Both groups were matched for appropriate age. The mean age for Group 1 was 64.23 years and group 2 was 64.83 . There was no statistical significance between the various age groups between both groups with a p value of 0.79 .

Comorbid illnesses: There was no statistical significance in concern with presence of any of the comorbid illness like diabetes mellitus, hypertension, ischemic heart disease, COPD, pulmonary tuberculosis between the two groups with a $\mathrm{p} 0.553$.

Previous history of AUR:_Even though most of the patients in both groups had no previous AUR episodes, there exists a statistical significance between group 1 and group 2 with respect to past history of urinary retention with a p 0.010 .

Tab 4 Comparison of various factors in both groups

\begin{tabular}{|l|c|c|c|}
\hline Factors & $\begin{array}{c}\text { Group 1 } \\
\mathrm{n}=30\end{array}$ & $\begin{array}{c}\text { Group 2 } \\
\mathrm{n}=30\end{array}$ & P value \\
\hline Age & 64.23 & 64.83 & 0.790 \\
\hline Comorbid illnesses & $\mathrm{n}=18$ & $\mathrm{n}=16$ & 0.553 \\
\hline $\begin{array}{l}\text { Previous history of } \\
\text { urinary retention }\end{array}$ & $\mathrm{n}=10$ & $\mathrm{n}=2$ & 0.010 \\
\hline IPSS grading score & 20.6 & 15.3 & 0.000 \\
\hline $\begin{array}{l}\text { Digital rectal } \\
\text { examination } \\
\text { grading }\end{array}$ & $\begin{array}{c}\text { Grade II } \\
(2-3 \mathrm{~cm})\end{array}$ & $\begin{array}{c}\text { Grade I (1-2 } \\
\mathrm{cm})\end{array}$ & 0.213 \\
\hline $\begin{array}{l}\text { Intravesical prostate } \\
\text { projection(mm) }\end{array}$ & $\begin{array}{c}\text { Grade II } \\
(5-10 \\
\text { mm) }\end{array}$ & $\begin{array}{c}\text { Grade 0 } \\
\text { (no } \\
\text { intravesical } \\
\text { projection) }\end{array}$ & 0.011 \\
\hline $\begin{array}{l}\text { Prostate size wall } \\
\text { (gms) }\end{array}$ & 6.13 & 35.43 & 0.003 \\
\hline $\begin{array}{l}\text { Bladder culture } \\
\text { thickness (mm) }\end{array}$ & $\mathrm{n}=15$ & $\mathrm{n}=12$ & 0.615 \\
\hline $\begin{array}{l}\text { Sr PSA(ng/ml) } \\
\text { Srine }\end{array}$ & 50.97 \\
\hline $\begin{array}{l}\text { Urinesitivity } \\
\text { pong }\end{array}$ & 3.59 & 0.026 \\
\hline
\end{tabular}

IPSS severity and grading: Most of the patients in both groups [group1 $(\mathrm{n}=21)$, group2 $(\mathrm{n}=27)$ ] presented with moderate IPSS score (8 -19).Mean 
IPSS score for group 1 was 20.6 and for group 2, 15.3 with a statistical significance, $\mathrm{p} 0.000$.

\section{Digital rectal examination- size grading}

Most of the patients in group 1(n=18) found to have grade II $(2-3 \mathrm{~cm})$ enlargement, and in group 2 $(n=14)$ had grade I enlargement $(1-2 \mathrm{~cm})$. There was no statistical significance observed among the two groups in concern with size grading of the prostate by digital rectal examination as shown by $\mathrm{p} 0.213$.

Size of prostate: Most of the patients in group $2(n=17)$ found to have grade I enlargement $(21-40$ gms) and in group $1 \quad(n=14)$ had grade II enlargement (41 -60 gms). Mean volume of the prostate gland was about 50.97gms in Group 1 and in the group 2 it was 35.43 with a statistical significance, $\mathrm{p} 0.003$.

Bladder wall thickness: Most of the patients in group $1(n=20)$ had thickness of more than $5 \mathrm{~mm}$, where as in the group $2(n=19)$ it was less than $5 \mathrm{~mm}$ with a statistical significance, p 0.020. Mean bladder wall thickness in Group 1 was $6.13 \mathrm{~mm}$ and in group 2 it was $5.5 \mathrm{~mm}$ with statistical significance, $\mathrm{p} 0.020$.

Intra vesical protrusion of prostate: Most of the patients in group $1(n=11)$ had grade II intra vesical protrusion of prostate $(5-10 \mathrm{~mm})$ whereas, in the group $2(n=17)$ it was grade 0 (no intra vesical protrusion of prostate) with a statistical significance, p 0.010 .

Serum PSA: Most of the patients in group 2(n=18) had PSA $<4 \mathrm{ng} / \mathrm{ml}$ whereas, in the group $1(\mathrm{n}=26)$ there were equal number of patients with $<4 \mathrm{ng} / \mathrm{ml}$ and $4-10 \mathrm{ng} / \mathrm{ml}$. Mean PSA level in group 1 was about $6.02 \mathrm{ng} / \mathrm{ml}$ and in the group 2 it was $3.59 \mathrm{ng}$ $/ \mathrm{ml}$ with a statistical signifance, $\mathrm{p} 0.026$.

Urine culture and sensitivity: Most of the patients in both the groups [group1 $(n=15)$ \& group2 $(n=18)$ ] showed no organisms grown in urine culture. There was no statistical significance between the two groups in concern with urine culture positivity with a p 0.615 .

\section{Discussion}

Benign prostatic hyperplasia (prostatic inflammation ${ }^{6,7}$ prostatic infarction $^{8}$, alteration in Stromal and Epithelial ratio ${ }^{9}$ ), stricture urethra, spinal cord injury and diabetes mellitus (disruption of bladder innervation), postoperative status ${ }^{10}$, constipation $^{11}$, stroke(CVA), alcohol ingestion (central nervous system suppression and fluid overload) $^{12}$, urinary tract infection (acute inflammation and edema of the bladder mucosa with mucosal thickening), bladder overdistension ${ }^{13}$ (regional anesthesia, prolonged labour, long duration surgery) can all cause urinary retention.

Anti-cholinergic drugs (detrusor relaxation) and alpha agonists (increasing bladder outlet resistance) can cause AUR. Also drugs used for depression, allergies, Parkinson's disease (by anticholinergic actions), drugs used over-the-counter cold remedies (by alpha-agonistic) and non-steroidal antiinflammatory drugs (NSAIDS) ${ }^{14}$ cause AUR.

In the past, an episode of AUR was an absolute indication for surgery. Between twenty five to thirty percent of men who underwent transurethral resection of the prostate (TURP) in the past had AUR as their main indication for surgery. ${ }^{15} \mathrm{At}$ present only those patients who fails trial without catheter undergo surgery.

In contrast to patients presenting with symptoms only, TURP has been found to be associated with increased morbidity and mortality in men with AUR. Delayed TURP is associated with lower morbidity and mortality than urgent intervention in a patient who had an episode of AUR. Hence, it is justifiable to attempt primary prevention of AUR.

(i) Advanced age was an important risk factor for AUR, supported by Olmsted county study, (Jacebson et al) ${ }^{16}$ the physician health study (Meigs et al $)^{17}$ and Berges et al ${ }^{18}$.

(ii)Sasaki et $\mathrm{al}^{19}$ proposed presence of diabetes mellitus as one of the risk factor for AUR in BPH patients. Our study showed no significance. 
(iii) A study involving 5,792 BPH men. who were offered conservative management with drugs done by Emberton $\mathrm{M}$ et al showed that prior episode of acute urinary retention was a strong predictor of recurrent episodes of acute urinary retention ${ }^{20}$ were correlating well with our study.

Although the likelihood of a second event of acute urinary retention after a Trial voiding without catheter (TWOC) was about 38-56\%. The risk of recurrent retention depends on prostate size, amount of post void residual urinary volume and also the duration between catheterisation and the TWOC ${ }^{11}$.

A study involving large database of 165,527 men with BPH, with AUR conducted by Cathcart etal ${ }^{21}$ showed that an increase in recurrent AUR was seen in patients who have not undergone surgical intervention following AUR.

(iv) Symptom severity is one of the risk factor predicting AUR. This is very well correlating with various studies such as Olmsted county study, (Jacebson et al) ${ }^{16}$, the physician health study (Meigs et al) ${ }^{17}$, and Berges et $\mathrm{al}^{18}$,Also Marberger MJ et al 22 and the PLESS Study Group, Roehrborn CG et al ${ }^{23}$, Kaplan $\mathrm{S}^{24}$.

(v) Since no universally accepted nomenclature describing prostatic size by DRE is available, and there are no validated studies available for comparison for this predictor. However, prostate size as assessed by the DRE was the most significant factor in predicting the outcome of a trial without catheter (TWOC). The digital rectal examination (DRE)estimated prostate volume (15.9 g vs. $27.5 \mathrm{~g}$ ) was found to be one of the main difference between those able to void and those who were not. ${ }^{11}$

(vi) Increase in size of the prostate is an important risk factor that predicts AUR. Marberger MJ et al ${ }^{22}$ and the PLESS Study Group, Roehrborn CG et $\mathrm{al}^{23}$, Kaplan $\mathrm{S}^{24}$ showed that prostate volume was an important predictor for AUR.

(vii) Manieri et $\mathrm{al}^{25}$ reported BWT of $>5 \mathrm{~mm}$ was the good cut-off point to diagnose bladder outlet obstruction. Kessler et al. $(2006)^{26}$ showed that BWT $\geq 2.9 \mathrm{~mm}$ and Oelke et al.(2007) chose a cut-off of $2 \mathrm{~mm}$ as a guide for diagnosing bladder outlet obstruction. $^{27}$
Contrary to above evidence, Abhishek Jain et al (2010) did not observe any statistically significant difference between patients with AUR and without AUR in terms of bladder wall thickness. This may be attributed due to difference heterogeneous patients group and also variations in the patient duration of symptoms were not studied. ${ }^{28}$

(viii) There was good correlation between the degree of protrusion of the prostate into the bladder cavity and the severity of obstruction as measured by a properly conducted uroflowmetry. Patients with minimal protrusion and a funneling bladder neck had good flow rates, whereas those with large intravesical protrusion had poor flow rates. In a study conducted by Tan and Foo et $\mathrm{al}^{29}$ of 100 patients with AUR who underwent trial off catheter, a grade 3 IPP was found to predict $67 \%$ failure rate. In contrast, $64 \%$ of patients with grade 1 IPP were successful. In a study conducted by Chia et al. ${ }^{30}$ demonstrated that patients with grade 1 IPP were not obstructed, while $94 \%$ of grade 3 IPP were obstructed.

(ix) Studies of Marberger MJ et al ${ }^{22}$ and the PLESS Study Group, Roehrborn CG et al ${ }^{23}$, Kaplan $\mathrm{S}^{24}$ showed that increased serum PSA levels was an important predictor for AUR correlating with our study.

(x) Contrary to studies, John M Fitzpatrick et al $(2012)^{31}$, Muruganandham et $\operatorname{al}(2007)^{32}$, Herbert Lepor et al $(2006)^{33}$ considered, urinary tract infection (UTI) as a risk factor for AUR, our study did not found any statistically significant difference between both groups .

\section{Conclusion}

Symptom severity, previous AUR episodes, high serum PSA levels, increased size of prostate, increased bladder wall thickness, increased intravesical prostatic projection are accurate predictors of acute urinary retention in patients with benign prostatic hyperplasia. Those patients who are at risk can be offered earlier treatment options, could be either medical or surgical intervention to prevent AUR. 
Bibliography

1. Bosch JL, Hop WGJ, Kirkles WJ et al. Natural history of benign prostatic hyperplasia: appropriate case definition and estimation of its prevalence in the community. Urology 1995; 46: 34-40.

2. Guess HA: Benign prostatic hyperplasia: antecedents and natural history. Epidemiology Rev1992; 14: 131-153.

3. Barry MJ, Fowler FJ, Bin L, et al. The natural history of patients with benign prostatic hyperplasia as diagnosed by North American urologists. J Urol. 1997; 157:10-15.

4. Acute Urinary Retention: Risks and Management Rev Urol. 2005; 7(Suppl 4): S31-S41. Claus G Roehrborn, MD

5. Manickam Ramalingam, David albala Textbook on benign prostatic hyper plasia $2012,1,20-21$

6. Kefi A, Koseoglu H, Celebi I, Yorukoglu K, Esen A. Relation between acute urinary retention, chronic prostatic inflammation and accompanying elevated prostate-specific antigen. Scand J UrolNephrol 2006; 40:155-60.

7. Kramer G, Mitteregger D, Marberger M. Is benign prostatic hyperplasia $(\mathrm{BPH})$ an immune inflammatory disease? EurUrol 2007; 51:1202-16.

8. Graversen PH, Gasser TC, Wasson JH, et al. Controversies about indications for transurethral resection of the prostate [review] J Urol. 1989;141:475-481.

9. Terris MK. Ultrasonography and biopsy of the prostate. In : Walsh PC, Retik $1 \mathrm{AB}$, Vaughan ED, Wein AJ, editors. Campbell's urology. 5 th ed. WB Saunders Co: Philadelphia; 2003. p. 3038-54.

10. Keita H, Diouf E, Tubach F, Brouwer T, Dahmani S, Mantz J, et al. Predictive factors of early postoperative urinary retention in the post anesthesia care unit. AnesthAnalg 2005; 101:592-6.
11. Kumar V, Marr C, Bhuvangiri A, Irwin P. A prospective study of conservatively managed acute urinary retention: prostate size matters. BJU Int. 2000;86:816-819

12. Stimson JB, Fihn SD. Benign prostatic hyperplasia and its treatment [review] J Gen Intern Med. 1990; 5:153-165.

13. Powell PH, Smith PJ, Feneley RC. The identification of patients at risk from acute retention. Br J Urol. 1980; 52:520 522.

14. Barclay L. NSAIDs may double the risk of acute urinary retention in men. Arch Intern Med 2005; 165:1547-51.

15. Klarskov P, Andersen JT, Asmussen CF, et al. Symptoms and signs predictive of the voiding pattern after acute urinary retention in men. Scand J UrolNephrol. 1987; 21:23-28.

16. Jacobsen SJ, Jacobson DJ, Girman CJ, et al. Natural history of prostatism: risk factors for acute urinary retention. J Urol. 1997; 158:481-487.

17. Meigs JB, Barry MJ, Giovannucci E, et al. Incidence rates and risk factors for acute urinary retention: the health professional's follow-up study. J Urol. 1999; 162:376-382.

18. Berges R, Pientka L, Hofner K, et al. Herner LUTS Study: incidence of acute urinary retention in the elderly men in Germany. J Urol. 2000; 163(4 suppl):252.

19. Sasaki K, Yoshimura N, Chancellor MB. Implications of diabetes mellitus in urology. UrolClin North Am. 2003; 30(1):1-12.

20. Emberton M, Lukacs B, Matzkin H, Alcaraz A, Elhilali M, Vallancien G. Response to daily $10 \mathrm{mg}$ alfuzosin predicts acute urinary retention and benign prostatic hyperplasia related surgery in men with lower urinary tract symptoms. J Urol 2006; 176: 1051-6. 
21. Cathcart P, van der Meulen J, Armitage $\mathrm{J}$, Emberton M. Incidence of primary and recurrent acute urinary retention between 1998 and 2003 in England. J Urol 2006; 176:200-4.

22. Marberger MJ, Andersen JT, Nickel JC, et al. Prostate volume and serum prostate-specific antigen as predictors of acute urinary retention. Combined experience from three large multinational placebo-controlled trials. Eur Urol. 2000; 38:563-568.

23. Roehrborn CG, Bruskewitz R, Nickel $\mathrm{GC}$, et al. Urinary retention in patients with $\mathrm{BPH}$ treated with finasteride or placebo over 4 years. Characterization of patients and ultimate outcomes. The PLESS Study Group. Eur Urol. 2000; 37:528-536.

24. Kaplan S, Garvin D, Gilhooly P, et al. Impact of baseline symptom severity on future risk of benign prostatic hyperplasia- related outcomes and longterm response to finasteride. The PLESS Study Group. Urology. 2000; 56:610616.

25. Manieri C, Carter SS, Romano G, Trucchi A, Valenti M, Tubaro A.The diagnosis of bladder outlet obstruction in men by ultrasound measurement of bladder wall thickness. J Urol 1998; 159:761.

26. Kessler TM, Gerber R Burkhard FC, Studer UE, Danuser H. Ultrasound assessment of detrusor thickness in men: Can it predict bladder outlet obstruction and replace pressure flow study? J Urol 2006; 175:2170-3.

27. Oelke M, Hofne k, Jonas U, de la Rosette J, Ubbink D, Wijkstra H. Diagnostic accuracy of non-invasive tests to evaluate bladder outlet obstruction in men: Detrusor wall thickness, Uroflowmetry, post void residual urine and prostate volume. EurUrol 2007;52:827-34

28. Abhishek Jain, SN Sankhwar, Apul Goel. Bladder wall thickness for the assessment of voiding dysfunction ,IJU .2010;26;319- $320-2$

29. Tan YH, Foo KT.Intravesical prostatic protrusion predicts the outcome of a trial without catheter following acute urine retention. J UroI2003; 170:2339-2341.

30. Chia SJ, Heng CT, Chan SP, Foo KT. Correlation of intravesical prostatic protrusion with bladder outlet obstruction. BJU Int 2003; 91:371-374.

31. John M Fitzpatrick, François Desgrandchamps, Kamel Adjali, Lauro Gomez Guerra, Sung Joon Hong, Salman El Khalid, and KrisadaRatana-OlarnManagement of acute urinary retention: benign prostatic hyperplasiaBJU;2012;109(1);88-95.

32. K Muruganandham, Deepak Dubey, Rakesh Kapoor. Acute urinary retention in benign prostatic hyperplasia: Risk factors and current management, IJU; 2007; 23; $347-353$.

33. Herbert Lepor, MD-Managing and Preventing Acute Urinary Retention; Rev Urol. 2005; 7(Suppl 8): S26-S33. 